\section{SOI: $1.1 / \mathrm{TAS} \quad$ DOI: $10.15863 / \mathrm{TAS}$ International Scientific Journal Theoretical \& Applied Science}

p-ISSN: 2308-4944 (print) e-ISSN: 2409-0085 (online)

Year: $2015 \quad$ Issue: $10 \quad$ Volume: 30

Published: $30.10 .2015 \quad$ http://T-Science.org

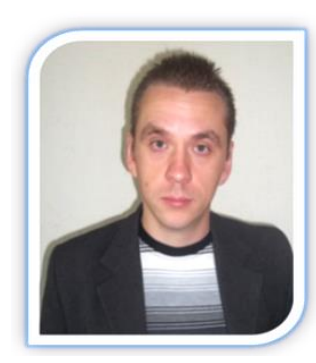

Denis Alexandrovich Chemezov Master of Engineering and Technology,

Corresponding member of International Academy of Theoretical and Applied Sciences, Lecturer of Vladimir Industrial College, Russia chemezov-da@yandex.ru

SECTION 7. Mechanics and machine construction.

\title{
THE RESEARCH OF THE SHALLOW DRAWING PROCESS OF THE PLATE STOCK
}

Abstract: The article considers the character of the deformation of the plate stock, made of aluminum alloy, at formation cups of the shallow drawing method.

Key words: shallow drawing, plate stock, deformation, die.

Language: English

Citation: Chemezov DA (2015) THE RESEARCH OF THE SHALLOW DRAWING PROCESS OF THE

PLATE STOCK. ISJ Theoretical \& Applied Science 10 (30): 11-15.

Soi: http://s-o-i.org/1.1/TAS-10-30-4 Doi: crossef http://dx.doi.org/10.15863/TAS.2015.10.30.4

\section{INTRODUCTION}

Drawing of the plate stock is a process of forcing through material by punch in the die opening, thereby forming a thin-walled hollow detail of different configuration [1].

The process of changing of the form of the plate stock during the shallow drawing is accompanied by radial, tangential, and axial deformations of the material [2]. Pressure end surface of the punch on the free surface of the plate stock, which is located coaxially with the die opening, leads to loss of stability of deformable billet. Part of the plate stock that is in contact with the surface of the die and is not fixed, begins to climb. Concurrently on a flat surface of the plate stock formed by the wrinkles (corrugations) [3, 4], which can cause unequal drawing of the material and, consequently, obtaining the wrong form of the detail. This occurrence is inherent during the shallow drawing of the plate stock of small thickness, without the use of holddown plate [5]. The elimination of the corrugation of the material occurs with increasing thickness of the plate stock.

Analysis of deformation mechanism of the plate stock in the conditions of its processing by pressure method shallow drawing will allow to make a prediction about a possible partial destruction of the material in areas subject to the maximum stress.

\section{MATERIALS AND METHODS}

The calculation of stress-strain state of the material plate stock was performed in dynamic mode by means of the software environment LS-DYNA [6].

Split into finite elements, the dimensions of the solid-state model and scheme of shallow drawing of the process of the plate stock is presented in Fig. 1.

The material of the plate stock - aluminum deformable alloy 1050 [7]. The material of the punch and die - alloy tool steel X165CrMoV12 [8].

The model of die, during all time the shallow drawing process, not displacement around the coordinate axes. The execution of the conical surface of the die opening allows reducing the stress in the material of the plate stock at a pressure of the punch. Axial line of the model of the punch was aligned with the axial line of the die opening. Model of the punch is displacement only in the direction of coordinate axis $\mathrm{Z}$ to the die. The plate stock is placed between the punch and the die. The outer diameter of the punch $d_{p}$ was defined according to the formula $d_{p}$ $=D_{d}-2 h(\mathrm{~mm})$, where $D_{d}-$ diameter of the die opening, mm; $h$ - thickness of the plate stock, mm. To reduce the friction of the surfaces of the tool on the walls deformable of the plate stock, the outer diameter of the punch make less on $0.1-0.15 \mathrm{~mm}$.

Calculated number of finite elements: model of the punch -19953 , model of the plate stock -6050 , model of the die -180036 . Size of element $-2 \mathrm{~mm}$, minimum edge length $-0.86 \mathrm{~mm}$.

The force acting on the punch, take constant and equal to $120 \mathrm{kN}$. The time spent on the deformation of the plate stock amounted to $0.2 \mathrm{~min}$. 


\begin{tabular}{|c|c|c|c|c|c|c|}
\hline Impact Factor: & $\begin{array}{l}\text { ISRA (India) } \\
\text { ISI (Dubai, UAE } \\
\text { GIF (Australia) } \\
\text { JIF }\end{array}$ & $\begin{array}{l}=1.344 \\
=0.829 \\
=0.356 \\
=1.500\end{array}$ & $\begin{array}{l}\text { SIS (USA) } \\
\text { PИHЦ (Russia) } \\
\text { ESJI (KZ) } \\
\text { SJIF (Morocco) }\end{array}$ & $\begin{array}{l}=0.912 \\
=0.179 \\
=1.042 \\
=2.031\end{array}$ & ICV (Poland) & $=6.630$ \\
\hline
\end{tabular}

(A)

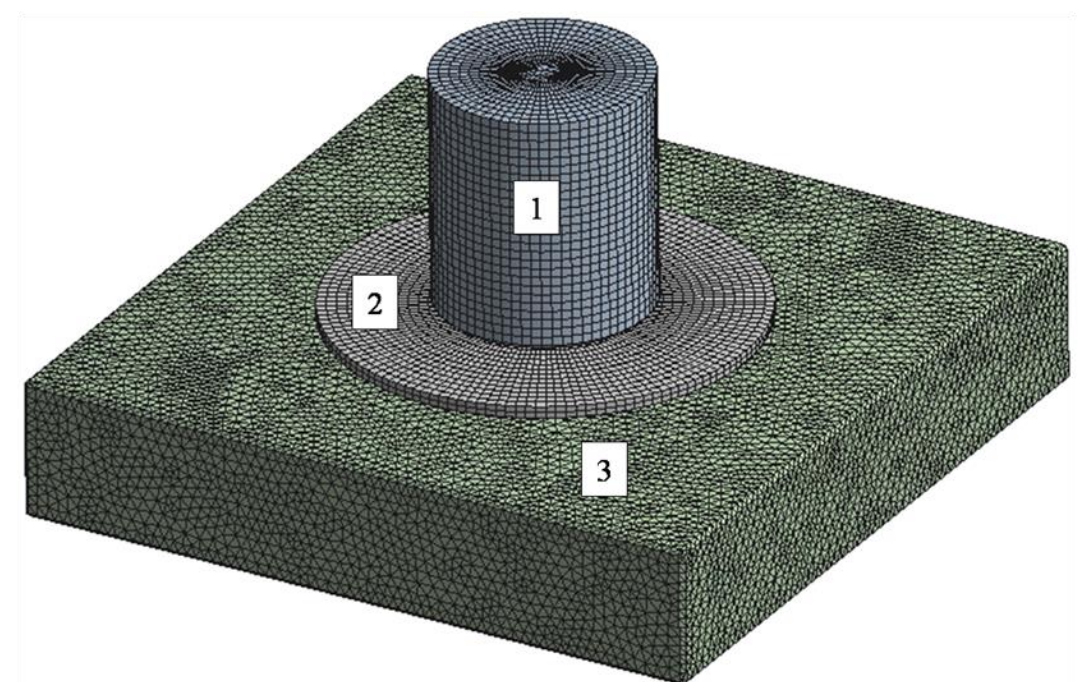

(B)

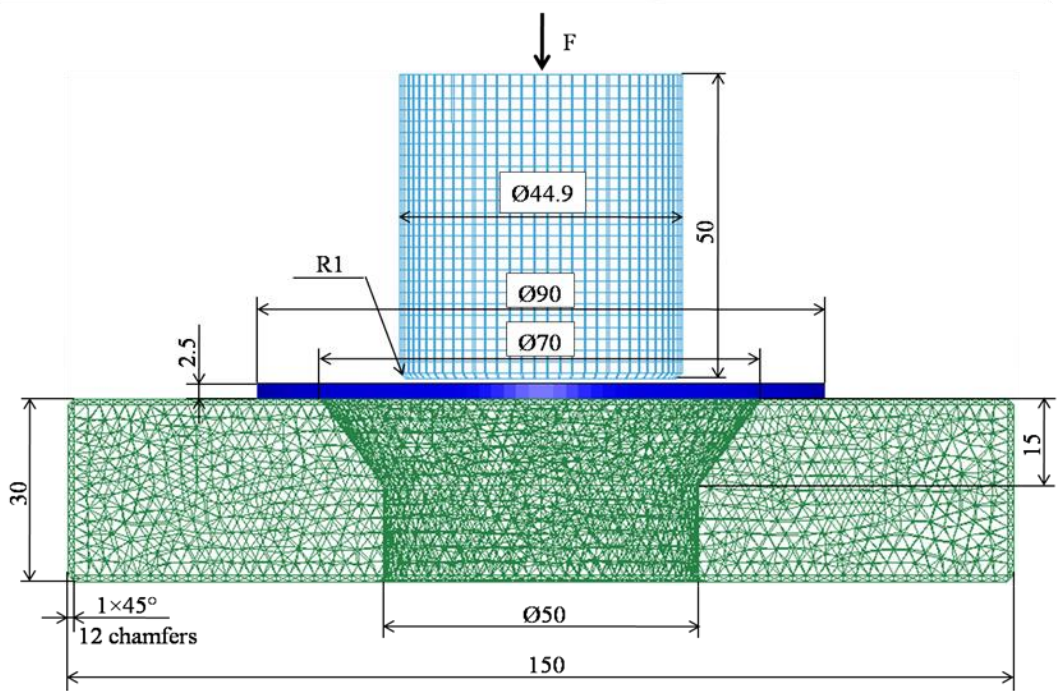

Figure 1 - A - Split into finite elements (finite element mesh) of solid-state volume models: 1 - punch (rigid body), 2 - plate stock (plastic material), 3 - die (rigid body); B - Scheme of the shallow drawing process of the plate stock and dimensions of models. $F$ - the force acting on the punch.

\section{RESULTS AND DISCUSSION}

The deformation of the plate stock, after the shallow drawing process and the value von Mises stress is presented in Fig. 2.

On the deformed of the plate stock is visible as formed of the wrinkles as a result of partial forcing through of material in a stepped of the die opening. These wrinkles are unevenly distributed. Thus, it is noted that the value of stress of the material of the plate stock on the area of the pressure of the punch (about $20.0 \mathrm{~N} / \mathrm{mm}^{2}$, the contours are marked in blue color) in 3.5 times less than the stress of the material located in the cylindrical surface of the die opening (an average of $70.0 \mathrm{~N} / \mathrm{mm}^{2}$, the contours are marked in yellow color) and 5 times less than the stress of the material at the place formation of wrinkles (an average of $97.0 \mathrm{~N} / \mathrm{mm}^{2}$, the contours are marked in red color)

Thus, the formation of wrinkles of the plate stock, which is subjected to shallow drawing without the use of hold-down plate, leads to appearance of local stresses of considerable value and possible destruction of the material.

The direction and magnitude of deformations velocities of the material in the cross section of the plate stock is presented on the vector diagram (Fig. 3).

The wall thickness of the plate stock model is equal to two finite elements. Arrows of different colors, in the cross section of the model indicate the direction and value of material deformation.

In the cross section of the model of the plate stock it is possible to allocate following deformation zones:

1. In part of the material, which is located in the conical surface of the die opening, deformation occurs in the direction of displacement of the plate stock at a given angle (different to the velocity of a characteristic for unequal shallow drawing of the plate stock); 
2. In part of the material, which is located in the cylindrical surface of the die opening (formation of configuration, the outer and inner diameters of the detail), there is a change of direction of deformation and thickness reduction of the plate stock in the place of transition of the conical surface into the cylindrical surface. The surface layer of the plate stock, facing to the punch, has a large velocity of deformation, than the surface layer, facing to the die opening;

3. In part material, on which is directly produced by the pressure punch (forming the bottom of detail), the deformation velocity is directed opposite to the displacement of the spinning tool (the elastic deformation is closer to the axis of the punch). The value of the deformation velocity of the material varies from 0.4 to $2.0 \mathrm{~mm} / \mathrm{s}$.

The dependence of the kinetic energy that is expended on the deformation of the plate stock, from time of the shallow drawing process is presented in Fig. 4.
The dependency is described by four nonlinear increasing and decreasing functions:

1. The first function - the increase in kinetic energy from 0 to $28 \mathrm{~J}$ in the time interval $0-0.5 \mathrm{~s}$, corresponds to the beginning of the process of elastic-plastic material deformation, i.e. bending and the formation of wrinkles on the surface of the plate stock;

2. The second function - the decrease in kinetic energy from 28 to $10 \mathrm{~J}$ in the time interval $0.5-1.5$ $\mathrm{s}$, corresponds to the elastic deformation of the material, i.e. restore the original form of the plate stock;

3. The third function - the increase in kinetic energy from 10 to $64 \mathrm{~J}$ in the time interval $1.5-13.5$ $\mathrm{s}$, corresponds to the basic process of forcing material through the die opening;

4. The fourth function - the decrease in kinetic energy from 64 to $25 \mathrm{~J}$ in the time interval $13.5-20$ $\mathrm{s}$, corresponds to the process of formation final configuration of the detail and smoothing of wrinkles.
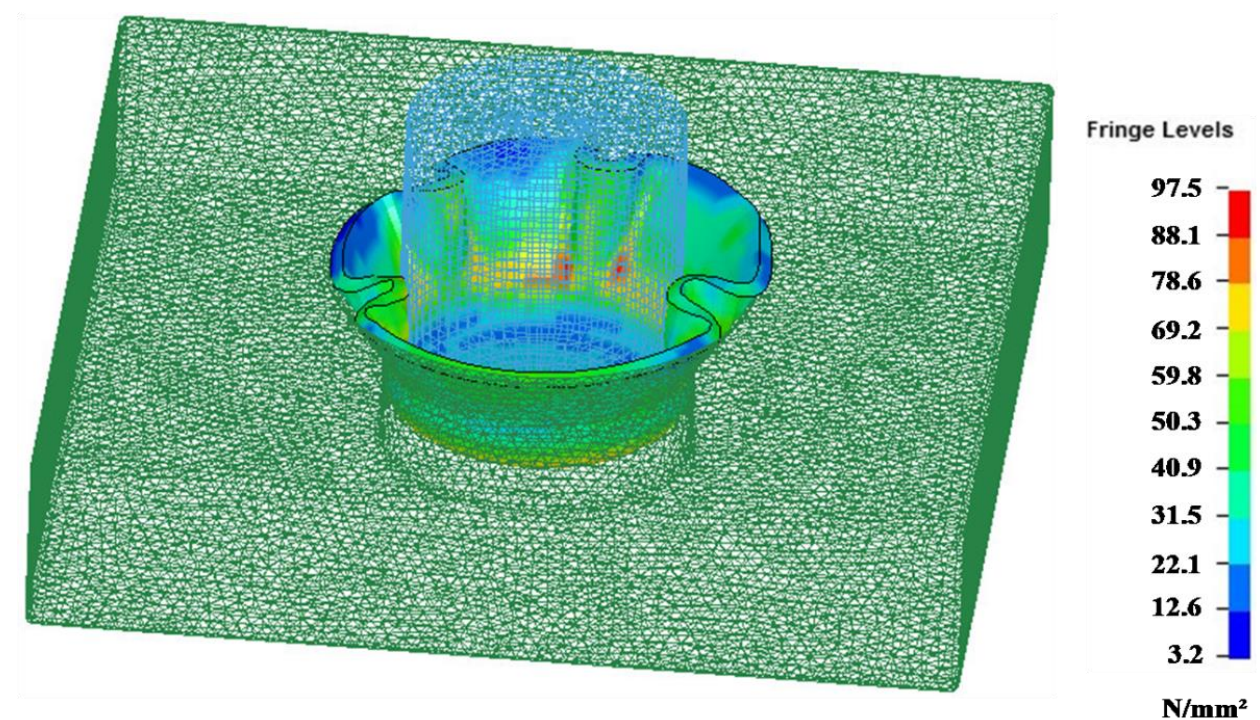

Figure 2 - Strain state of the plate stock at the end of the shallow drawing process. Colors on the model of the plate stock - the intensity of the von Mises stress of the material. 


\begin{tabular}{|c|c|c|c|c|c|c|}
\hline Impact Factor: & $\begin{array}{l}\text { ISRA (India) } \\
\text { ISI (Dubai, UAE } \\
\text { GIF (Australia) } \\
\text { JIF }\end{array}$ & $\begin{array}{r}=1.344 \\
=0.829 \\
=0.356 \\
=1.500\end{array}$ & $\begin{array}{l}\text { SIS (USA) } \\
\text { PИНЦ (Russia) } \\
\text { ESJI (KZ) } \\
\text { SJIF (Morocco) }\end{array}$ & $\begin{array}{l}=0.912 \\
=0.179 \\
=1.042 \\
=2.031\end{array}$ & ICV (Poland) & $=6.630$ \\
\hline
\end{tabular}

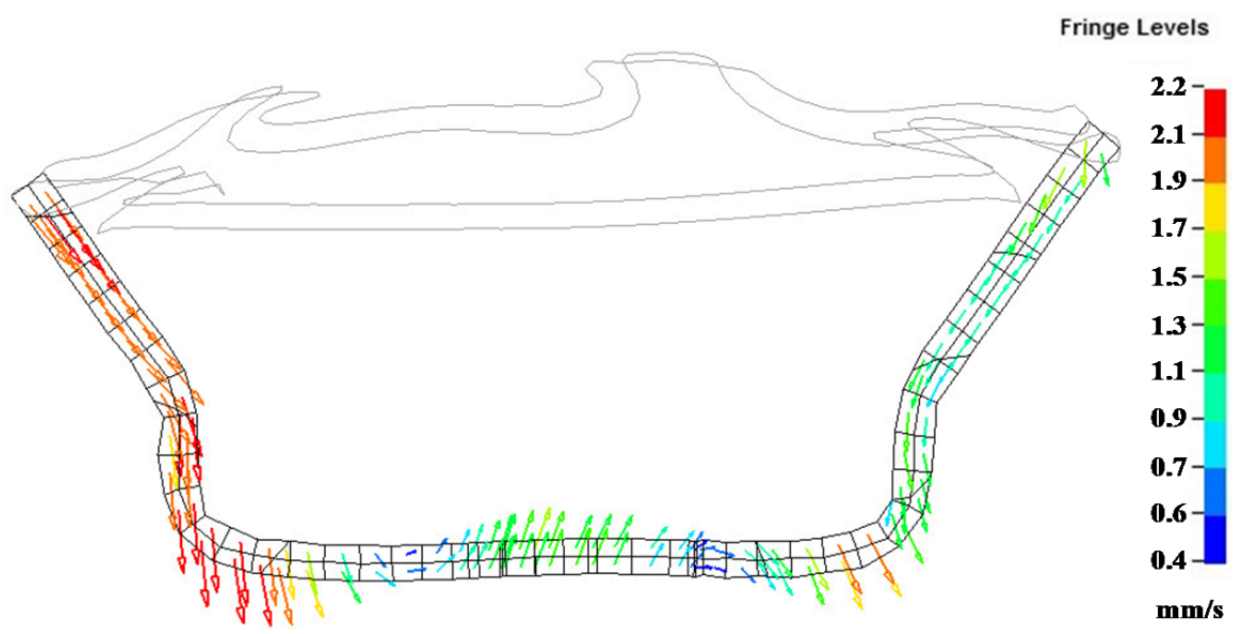

Figure 3 - The vectors of deformation velocity of material in the cross section of the plate stock.

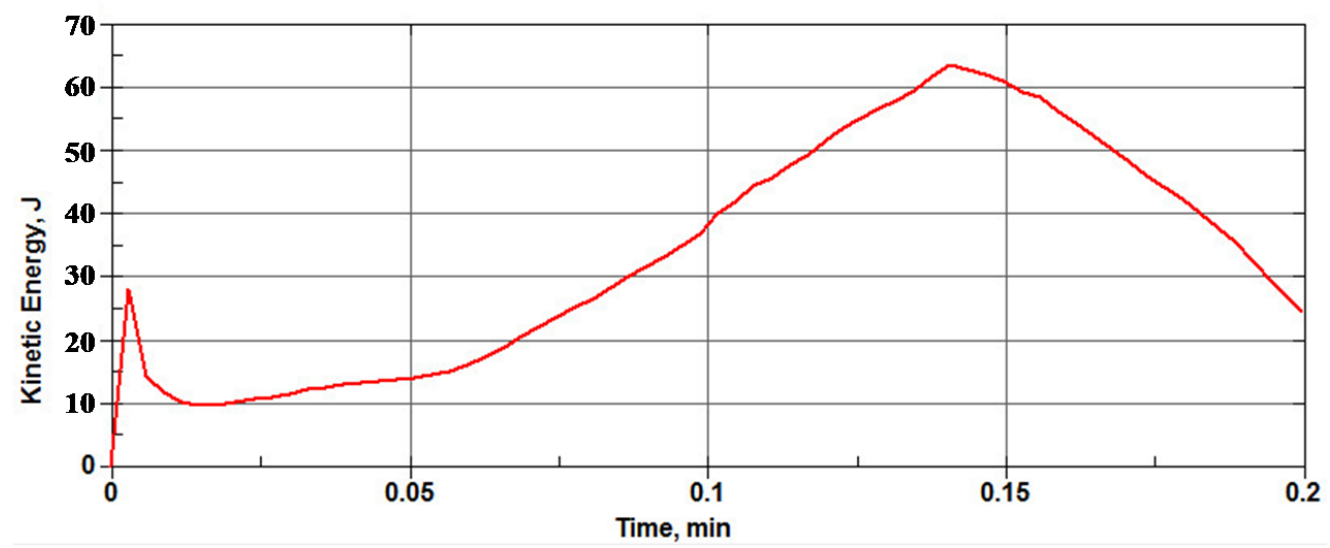

Figure 4 - The dependence of the kinetic energy that is expended on the deformation of the plate stock, from time of the shallow drawing process.

\section{CONCLUSION}

According to the results of computer simulation of shallow drawing process of the plate stock, made of aluminum alloy, we can make the following conclusions:

1. The formation of wrinkles on the surface of the deformable plate stock and the subsequent offset relative to the axis of the die opening, leads to the asymmetry of the contour of the detail.

2. The maximum von Mises stress distributed on the bending of the plate stock is 50 to $100 \mathrm{~N} / \mathrm{mm}^{2}$.

3 . The highest deformation velocity of the material is observed on the bending of the plate stock, formed by the radius on the edge of the punch.

\section{References:}

1. (2015) Protsess vytyazhki listovyh metallov. Available: $\quad$ http://omd.omgtu.ru/wpcontent/themes/iGadgets/basetlsh/80-90.htm (Accessed: 02.10.2015).

2. (2015) Odnooperacionnaya vytyazhka. Vidy vytyazhka. Available: http://proizvodim.com/odnooperacionnaya- vytyazhka-vidy-vytyazhki.html 02.10.2015).

(Accessed:

3. Yakovlev SS, Remnev KS, Kalashnikov AE, Korotkov VA (2014) Experimental researches anisotropic folding the blank workpieces at drawing. "Proceedings of the TSU". Vol. №6/2014. - Pp. 35 - 45. 


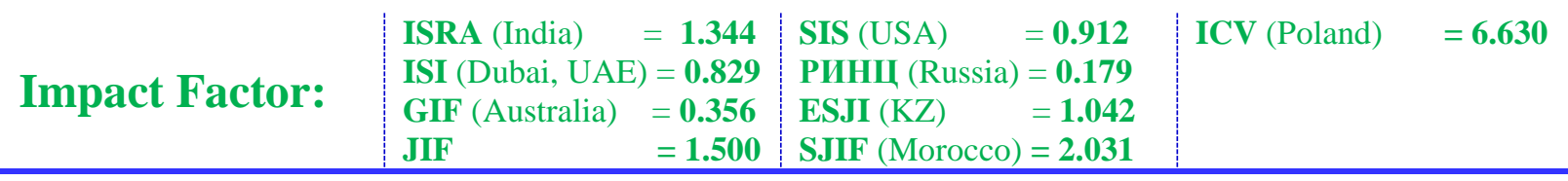

4. Popov IP, Nesterenko YS (2007) Inereasing limit coefficient of thin material drawing in a die with an elastic element (holder). Vestnik of the Samara State Aerospace University. №1, 2007. - Pp. $201-206$.

5. (2015) Vytyazhnye shtampy - shemy. Available: http://mash-xxl.info/info/71571/ (Accessed: 02.10.2015).

6. (2015) LS-DYNA. Available: http://www.lstc.com/products/ls-dyna (Accessed: 02.10.2015).
7. (2015) Aluminium Alloy 1050. Available: http://www.aalco.co.uk/datasheets/Aluminium -Alloy-1050A-H14-Sheet 57.ashx (Accessed: 02.10.2015).

8. (2015) Steel Grades: Tool Steel And Hard Alloy: X165CrMoV12. Available: http://steelgr.com/Steel-Grades/Tool-SteelHard-Alloy/x165crmov12.html (Accessed: 02.10.2015). 